\title{
CONFERENCIA: COMISO DE ACTIVOS EN LOS ESTADOS UNIDOS
}

\author{
Stefan D. Cassella*
}

\section{INTRODUGGIÓN}

Se me ha pedido proporcionar una perspectiva general acerca del comiso de activos en los Estados Unidos, pero primero debo proporcionar algún contexto, contestando algunas preguntas:

¿Cómo funciona el sistema de justicia penal en los Estados Unidos, y cómo encaja en este la recuperación de activos?

¿Estamos hablando de un programa federal? ¿Un programa estatal? ¿Es esto algo que siempre se hace en una corte penal? ¿Hay cortes civiles separadas?

¿Y cuál es el alcance del programa? ¿Qué clases de bienes pueden ser recuperados? ¿En qué clases de casos? ¿Cuánto dinero es recuperado y a dónde va?

Luego corresponde hablar sobre objetivos: diferente?

¿Cuál es el objetivo de la recuperación de activos? ¿Es castigo, disuasión, o algo Y hablaré sobre procedimiento:

¿Cómo se desarrolla un caso típico?

¿Cuáles son los roles de los investigadores, los fiscales y las cortes?

¿Cuándo trataríamos de recuperar bienes como parte de un caso penal, y cuándo comenzaríamos una acción civil (o NGB) separada?

Este último punto me llevará a algunos ejemplos de recuperación de activos en el contexto internacional.

¿Podemos utilizar el comiso de activos para recuperar bienes en los Estados Unidos que provienen de un delito extranjero?

¿Podemos recuperar bienes en un país extranjero que provienen de un delito ocurrido en los Estados Unidos?

¿Podemos recuperar bienes si el acusado ha huido y es ahora un fugitivo en otro país?

\footnotetext{
Asset Forfeiture Law, LLC, Estados Unidos (Cassella@AssetForfeitureLaw.us). Este artículo es una versión editada de una presentación dada en el Seminario sobre Recuperación de Activos Estatales y Regulación de la Confiscación en Chile, 19 de abril de 2018, en la Universidad Adolfo Ibáñez, Santiago, Chile. Traducción de Mauricio Reyes.
} 
¿Podemos hacer cumplir una sentencia de comiso dictada por una corte extranjera, y pueden cortes extranjeras hacer cumplir nuestras sentencias?

Finalmente, me gustaría discutir cómo hemos atendido ciertas cuestiones constitucionales que emergen en casos de recuperación de activos. Por ejemplo:

¿Quién tiene la carga de la prueba?

¿Hay un derecho a sostener una defensa de dueño inocente [an innocent owner defense]?

¿Pueden utilizarse los productos del delito para pagar un abogado?

¿Debe el comiso ser proporcional al delito?

\section{ESTRUCTURA DE LA JUSTIGIA PENAL EN LOS ESTADOS UNIDOS}

Permítanme comenzar con algún contexto: cómo funciona el sistema de justicia penal en los Estados Unidos.

Somos un sistema federal con un gobierno nacional y cincuenta gobiernos estatales separados. Entonces, tenemos un sistema penal federal y cincuenta sistemas estatales separados de justicia penal. Eso significa que tenemos leyes federales de comiso de activos y fiscales federales que las hacen cumplir en cortes federales, y leyes estatales de comiso de activos con fiscales estatales que las hacen cumplir en cortes estatales.

Las leyes estatales varían de estado en estado en cuanto a qué tan frecuentemente estas son usadas, qué recursos están destinados a ellas, qué procedimientos son empleados, y cuántos bienes son recuperados. Una gran variable es el tamaño del estado: el comiso bajo la ley estatal en un estado grande, como California, puede ser muy diferente al comiso en un estado más pequeño, como Alaska o New Hampshire.

\subsection{El programa federal de comiso}

Mi foco, sin embargo, está en el sistema federal. Todos los casos importantes - los enormes casos de drogas, los enormes casos de fraude, los casos de corrupción pública importantes (incluyendo la alegación de que Rusia habría manipulado las elecciones en Estados Unidos) y casos que involucran los activos provenientes de un delito extranjero lavados en los Estados Unidos- son todos casos federales. Y el programa federal de comiso es muy grande y robusto: en un año típico recuperamos sobre dos billones de dólares en activos de origen delictivo: alrededor de la mitad en casos de drogas y la mitad en casos que involucran fraude, corrupción y otros crímenes sofisticados.

Fui un fiscal federal durante treinta años, especializado en lavado de dinero y recuperación de activos. Trabajé en el Departamento de Justicia en Washington, que es la sede nacional del programa federal de recuperación de activos, y también trabajé en dos de nuestras oficinas regionales. El Departamento de Justicia tiene 93 distritos u oficinas federales regionales en los Estados Unidos. Y terminé mi carrera 
hace algunos años como Jefe de la Sección de Lavado de Dinero y Comiso de la oficina del fiscal federal en Baltimore, Maryland, que es una de las 93 oficinas.

Entonces, acerca de lo que hoy hablaré es el comiso en el sistema federal de los Estados Unidos.

\section{2. ¿A dónde va el dinero?}

Ahora he dicho que recuperamos más de dos billones de dólares por año en el programa federal de comiso de activos. En algunos años, cuando ha habido una recuperación en un caso de fraude importante, es mucho más. Tuve un caso hace muchos años en el que recuperamos 1.200 millones en un solo caso ¿Pero a dónde va a parar el dinero?

En resumen, las víctimas siempre tienen preferencia: si hay víctimas, el dinero decomisado es destinado a reembolsarlas, a menos que el acusado tenga suficiente dinero para pagarle a las víctimas él mismo.

Si no hay víctimas, o si el acusado puede pagarles él mismo, el dinero va a un Fondo de Comiso de Activos, donde es utilizado para financiar entrenamiento, equipo y otras actividades. En muchos casos, el dinero puede ser compartido con los departamentos de policía estatales y locales que ayudaron a desarrollar el caso federal. Y en casos internacionales, si hay un acuerdo bilateral con otro país de compartir activos decomisados, los Estados Unidos compartirán los activos con ese país.

\section{3. ¿Quién investiga los casos? ¿A qué corte van?}

Los Estados Unidos son un país de common law, lo que significa que, a diferencia del sistema en jurisdicciones de derecho civil, nuestras cortes y jueces no toman parte en la investigación y persecución de casos penales. Estos casos son investigados por agencias de cumplimiento de la ley y presentados ante la corte por fiscales federales. Las cortes son puramente árbitros, deciden qué evidencia es admisible, qué derecho y procedimientos son aplicables, si el Gobierno ha probado su caso y, en casos penales, cuál debe ser la sentencia.

No tenemos distinción entre cortes penales y civiles. Hay casos civiles y penales, pero no cortes civiles y penales. Todos los jueces federales pueden conocer y de hecho conocen tanto casos penales como civiles, incluyendo tanto casos penales como casos civiles de recuperación de activos. Con respecto a estos últimos, es el fiscal quien decide si presenta un caso de comiso de activos como parte de una persecución penal o como una acción separada "no basada en condena" [non-conviction-based]. Cualquiera que sea la elección tomada, el caso va a la misma corte.

El comiso, en otras palabras, es una herramienta del fiscal: el fiscal decide qué herramienta usar; la corte decide si está siendo usada apropiadamente, y si el Gobierno ha probado que tiene derecho a recobrar bienes manchados [tainted property] por el delito. Dentro de un momento discutiré cómo es que el fiscal decide recuperar bienes en sede penal o en una acción de comiso "no basada en condena" separada, pero primero déjenme hablar sobre el proceso: ¿quién investiga los casos? 
Nosotros tenemos muchas agencias de cumplimiento de la ley en los Estados Unidos, y estas poseen diferentes áreas de responsabilidad. Por ejemplo, el FBI (Oficina Federal de Investigaciones) investiga casos de fraude y de corrupción, el IRS (Servicio de Rentas Internas) investiga casos de impuestos y de lavado de dinero, la DEA (Administración Antidrogas) investiga casos de drogas, HSI (Investigaciones de Seguridad Interior) investiga casos de contrabando, y así sucesivamente.

Típicamente, entonces, un caso se desarrolla de la siguiente manera: una de las agencias abre una investigación sobre un presunto delito; por ejemplo, el FBI podría abrir una investigación de un funcionario público corrupto o de una sofisticada trama de fraude. Cuando una agencia siente que la investigación ha alcanzado un cierto punto, los agentes la presentan ante un fiscal federal, quien puede decir que el caso está preparado, o puede sugerir investigación adicional.

No solo es responsabilidad de la agencia investigar el delito y reunir la evidencia necesaria para probarlo, sino además localizar los activos derivados del delito o que fueron utilizados para cometerlo. De ese modo, cuando el caso está preparado, el Gobierno está listo para incautar los activos.

Si el fiscal decide que el caso está listo, él o ella debe decidir si el Gobierno intentará recuperar los activos como parte de un caso penal o como una acción "no basada en condena" para recobrar el dinero sin ninguna condena penal. En ambos casos, el caso va a la misma corte federal, donde el Gobierno debe probar dos cosas: que un delito se cometió, y que los bienes que el Gobierno quiere recuperar derivaron de dicho delito o fueron usados para cometerlo.

En ambos casos, el acusado - $\mathrm{O}$ el propietario- tiene derecho a hacer que estas cuestiones sean determinadas por la corte o por un jurado, pero al final, si el Gobierno resulta exitoso, la corte emitirá una orden adjudicando la propiedad de los bienes a los Estados Unidos.

Siempre hay excepciones, desde luego - algunos casos son más complicados que otros - pero típicamente, un caso de pérdida de activos puede resolverse en alrededor de un año.

\section{POR QUÉ DEGOMISAR}

Dije que hablaría acerca de lo que nosotros vemos como el propósito de tratar de recuperar activos: ¿Cuáles son los objetivos de un programa de comiso de activos, y por qué le dedicamos tanto tiempo y energía al mismo?

Estos propósitos fueron expuestos por la jueza Elena Kagan de la Corte Suprema en Kaley v. United States $^{1}$ y pueden ser resumidos de la siguiente manera:

1 Kaley v. United States (2014), el comiso sirve para castigar al infractor, disuadir la ilegalidad futura, disminuir el poder económico de futuras empresas criminales, compensar a las víctimas, mejorar las condiciones en comunidades afectadas por el crimen, y apoyar actividades de cumplimiento de la ley tales como entrenamiento policial. 


\section{Castigar al infractor}

A muchos criminales les importa más conservar su dinero que lo que les preocupa cumplir condenas en la cárcel. Entonces, para castigar al imputado, el fiscal no busca únicamente meterlo en la cárcel, sino además quitarle los frutos del delito. Esto puede implicar hacerle pagar un fallo igual a los activos que recibió, incluso si ya ha gastado el dinero, e incluso si ha reembolsado a la víctima. ${ }^{2}$

\section{Disuadir a otros infractores}

En la mayoría de los casos, la finalidad de cometer el delito fue obtener dinero. Si no se le permite al imputado conservar el dinero, hay menos incentivos para que otras personas cometan el mismo delito. ${ }^{3}$

\section{Quitar las herramientas del oficio y los recursos económicos}

El comiso de activos también es una forma de incapacitación: no queremos que los narcotraficantes conserven el avión que usaron para traer drogas de contrabando, de modo que lo puedan emplear de nuevo. Y determinar cómo se financia el terrorismo y quitarles el dinero antes de que pueda ser usado, es una parte esencial del esfuerzo antiterrorista. Más importante con respecto al tema de este seminario, no queremos permitir que los líderes corruptos de otros países utilicen el sistema financiero de los Estados Unidos para saquear sus erarios y crear un fondo de reserva para cuando tengan que partir al exilio. Para prevenir eso, el dinero debe ser confiscado.

\section{Perturbar a la organización}

El dinero es el pegamento que mantiene unidas a las empresas criminales; el dinero debe ser reciclado para mantener la empresa en funcionamiento. Esto le da al Gobierno la oportunidad de perturbar la organización decomisando sus activos.

Por ejemplo, para una organización de narcotráfico es más difícil reemplazar el dinero derivado de la venta de drogas que reemplazar las drogas mismas. De ese modo, quitarle el dinero contribuye más a interrumpir el ciclo que cualquier número de arrestos en casos de flagrancia generada por agentes provocadores. Lo anterior también es cierto tratándose de personas involucradas en el tráfico de vida silvestre: decomisarle el dinero que fluye desde los mercados asiáticos a las empresas de caza furtiva es más efectivo que arrestar al cazador furtivo que está en el África con el camión y el arma. De manera similar, decomisar dinero destinado a países sancionados como Corea del Norte e Irán perturba su capacidad para evadir dichas sanciones.

2 United States v. Peters (2013), el propósito del comiso es el castigo; eso es lo que distingue al comiso de la restitución y de otras herramientas remediales; la restitución pone al imputado y a la víctima de vuelta en la posición en la que se encontraban antes de que el delito ocurriera; el comiso castiga al imputado al forzarlo a pagar los ingresos brutos del delito, no solamente la ganancia neta.

3 United States v. Martin (2011), el comiso penal es parte de la sentencia del imputado; su propósito es "privar a los criminales de los frutos de sus actos ilegales y disuadir futuros crímenes". 


\section{Devolverle dinero a la víctima}

El comiso de activos es una vía más efectiva para recobrar dinero para las víctimas que ordenarle al imputado pagar restitución. Como ha explicado una corte de apelaciones, "La capacidad del Gobierno de cobrar en una resolución [de comiso] con frecuencia sobrepasa por mucho la de una víctima no instruida o carente de medios económicos. . . Siendo realistas, la esperanza de una víctima de obtener pago puede descansar en la capacidad superior del Gobierno de cobrar y liquidar los activos del imputado" bajo las leyes de comiso. ${ }^{4}$

\section{Proteger a la comunidad}

Recobrar dinero de funcionarios públicos corruptos le da a los organismos que hacen cumplir la ley la oportunidad de demostrarle a la población en general que no se les permitirá a los infractores beneficiarse de sus crímenes, que el derecho trata a todos por igual, y que los funcionarios públicos no pueden actuar con impunidad. Asimismo, asegura que el campo de juego sea parejo, de manera que las personas que tratan de dirigir empresas honestamente no tengan que competir con capitales provenientes de fuentes ilegales.

\section{Reciclar el dinero}

Los fondos decomisados pueden ser compartidos con organismos de cumplimiento de la ley estatales y locales y usados para financiar programas de cumplimiento de la ley, y parte de los bienes decomisados puede ser destinada a un uso oficial o entregada a organizaciones comunitarias. Este es el asunto o aspecto controversial del programa de recuperación de activos, sin embargo, y debe ser administrado con cuidado. Cuando a las agencias de cumplimiento de la ley se les permite retener los bienes que han recuperado, estas pueden ser acusadas de "beneficiarse de la actividad policial" en lugar de hacer cumplir la ley para lograr un objetivo legítimo de cumplimiento de la ley.

\section{IV. ¿QUÉ SE PUEDE DEGOMISAR?}

Entonces, ¿qué clases de bienes están sujetos a comiso? ¿Estamos hablando de dinero, casa, autos, embarcaciones y aviones? ¿Estamos hablando del producto del delito o de algo más?

\subsection{Producto}

Generalmente, bajo la legislación federal, los Estados Unidos pueden recuperar los productos del delito. Eso significa que se puede recuperar cualquier bien que el imputado no tendría de no ser por haber cometido el delito.

4 United States v. Blackman (2014). 
En la mayoría de los casos, determinar qué bienes constituyen los productos del delito es bastante obvio. Si el imputado vendió drogas, el dinero que recibió por las drogas es el producto. Si robó un banco, cometió fraude, o aceptó un soborno, el dinero del banco o de la víctima del fraude o el pago del soborno sería el producto. Usualmente eso se expresa en términos de los ingresos brutos del imputado sin reducción de costos alguna. El narcotraficante, por ejemplo, no tiene derecho a deducir el costo de las drogas. ${ }^{5}$

En algunos casos, sin embargo, puede ser un poco más difícil determinar qué es lo que constituye el producto. Si un contratante obtiene un contrato mediante el pago de un soborno, ¿es el producto todo el dinero que recibe por concepto del contrato? ¿U obtiene crédito por el costo del trabajo que efectivamente efectuó? ${ }^{6}$

$\mathrm{Al}$ margen de este asunto, el alcance del término "producto" puede ser bastante amplio: "producto" incluye cualquier bien que se pueda reconducir a los productos, incluyendo cualquier incremento en el valor de dicho bien. ${ }^{7}$ Asimismo, bajo el test de la "condictio sine qua non" [but for test], una empresa completa y todas sus rentas y activos están sujetas a comiso si la empresa no hubiera existido a menos de que se hubiera invertido el producto del delito en iniciarla o mantenerla en funcionamiento. ${ }^{8}$

Finalmente, el "producto" de un delito puede estar integrado no solamente por bienes obtenidos directamente por el imputado como resultado del delito, sino que también por bienes retenidos por él u obtenidos por un tercero que actuó en concierto con él. Por ejemplo, si el imputado tiene una deuda, pero consigue que se la reduzcan por medio del pago de un soborno, el monto ahorrado sería el producto del soborno. ${ }^{9}$

5 United States v. Peters (2013), decomisar las ganancias del imputado no constituye castigo porque meramente lo reestablece en la posición económica que ocupaba antes de que cometiera el delito; por lo tanto, al imputado se le deben decomisar los ingresos brutos; United States v. McHan (1996), ingresos brutos decomisables en caso de narcotráfico; United States v. Keeling (2000), igual; United States v. Colon (2013), igual; United States v. Heilman (2010), igual; siguiendo a McHan. Sin embargo, véase United States v. Farrett (1998), afirmando el cálculo que le dio al imputado crédito por el costo de la heroína.

6 Véase United States v. Martin (2014), al contratante que obtiene un contrato con el Gobierno invocando falsamente que es elegible para un programa para empresas desaventajadas le deben ser decomisadas las ganancias netas, no los productos brutos, de los contratos obtenidos fraudulentamente.

7 United States v. Betancourt (2005), si el imputado compra un boleto de lotería con los productos del narcotráfico, las ganancias de la lotería son reconducibles al delito aun cuando el valor del boleto se apreció enormemente al resultar que contenía el número ganador.

8 United States v. Warshak (2010), todos los productos de los negocios del imputado son susceptibles de comiso, porque el negocio estaba "permeado con fraude;" pero incluso si una parte del negocio era legítima, los productos de esa parte son de todos modos susceptibles de comiso, si el lado legítimo del negocio no hubiera existido de no ser por los "inicios fraudulentos" de la operación completa; United States v. Smith (2014), siguiendo a Warshak; si el negocio está tan impregnado por el fraude que su flujo de ingresos no habría existido de no ser por el fraude, cualquier activo derivado de esos ingresos puede ser decomisado como producto.

9 United States v. Torres (2012), todo lo que se requiere es un "nexo causal entre la posesión de los bienes por parte del infractor y su delito"; dinero de renta que el imputado ahorró o retuvo como consecuencia del delito es producto obtenido "indirectamente"; United States v. Peters (2013), debido a que el estatuto hace al imputado responsable por los bienes obtenidos "directa o indirectamente", él es 


\subsection{Bienes facilitantes}

En los Estados Unidos y otros países, los bienes que son usados para cometer un delito son llamados "bienes facilitantes" [facilitating property]; en otros lugares se la llama el "instrumento" del delito. Como quiera que se los llame, el término puede ser muy amplio.

En esencia, un bien facilitante es cualquier cosa que haga que el delito sea más fácil de cometer o más difícil de detectar. ${ }^{10}$ En casos que se remontan a décadas, las cortes han sostenido el comiso de bienes raíces, vehículos y otros activos personales, en calidad de bienes facilitantes. ${ }^{11}$ De hecho, una empresa completa y/o todos sus activos podrían ser decomisados como bienes facilitantes. ${ }^{12}$

responsable por los productos obtenidos por una corporación que domina o controla, incluso si él no obtuvo el dinero personalmente; United States v. Olguin (2011), la disposición que autoriza el comiso de fondos obtenidos "directa o indirectamente" es la base estatutaria para la responsabilidad solidaria, haciendo a cada imputado responsable de los productos obtenidos por sus co-conspiradores, con independencia de si él mismo obtuvo parte alguna de los fondos

10 United States v. Schifferli (1990), una oficina dental "proveía un aire de legitimidad y protección frente al escrutinio externo" y por lo tanto hizo que el delito de escribir recetas falsas fuera menos difícil de cometer y "más o menos libre de obstrucción u obstáculo"; United States v. Huber (2005), los bienes facilitantes son cualquier cosa que "haga que la conducta prohibida sea menos difícil o más o menos libre de obstáculo"; United States v. Rivera (1989), definiendo bienes facilitantes en términos amplios.

11 Véase, p.ej., United States v. Diaz (2011), comiso de bienes raíces en los que el propietario permitía a narcotraficantes estacionar sus semirremolques mientras esperaban transportar drogas y dinero a través de la frontera; United States v. Ortiz-Cintron (2006), residencias donde los imputados empacaron drogas y almacenaron dinero proveniente del narcotráfico, y donde se hicieron llamadas telefónicas, fueron susceptibles de comiso como bienes facilitantes; United States v. Fuluke (2005), los bienes están sujetos a comiso como bienes facilitantes conforme al § 853(a) incluso si solo una porción de los mismos fueron utilizados para facilitar el delito; la residencia del imputado era susceptible de comiso aun cuando no se encontraron drogas en la casa porque estacionó su auto que contenía heroína en la calzada y guardó armas y dinero en la casa; United States v. Singh (2004), una licencia médica puede ser decomisada como bien facilitante bajo la sección 853(a)(2) si el doctor usa la licencia para distribuir sustancias controladas en infracción a la Ley de Sustancias Controladas (en el original: “Controlled Substances Act” N. del T.); bajo la sección 853(b), bajo bienes se incluyen "derechos, privilegios, intereses, pretensiones, y valores"; United States v. Harris (1990), bajo la sección 853(a)(2), bienes usados para facilitar un delito de narcotráfico pueden ser decomisados en su totalidad, incluso si solo parte de ellos fueron utilizados para el propósito ilegal.

12 Véase, p.ej., United States v. \$7708. 78 in U.S. Currency (2011), bienes facilitantes son cualquier cosa que haga que el delito sea "menos difícil o más o menos libre de obstrucción u obstáculo"; una farmacia usada como fachada para la distribución ilegal de drogas es susceptible de comiso como bien facilitante, y por lo tanto también lo son todos sus activos; incluyendo fondos en sus cuentas bancarias que incluyan dinero reconducible a ventas legítimas; United States v. Segal (2005), si una empresa es decomisada, entonces también lo son todos sus activos, incluyendo cualquier negocio subsidiario del que la empresa decomisada sea única propietaria; que no haya base independiente para el comiso de la subsidiaria es irrelevante. 


\section{RESUMEN DEL PROGEDIMIENTO DE COMISO}

Entonces, ¿cuál es el procedimiento para hacer todo esto? Muchos países tienen legislación que permite recuperar los activos por cualquiera de dos vías: como parte de la sentencia del acusado pronunciada tras su condena por un delito, o en un procedimiento de comiso no basado en condena ("NCB" o "civil"). En los Estados Unidos podemos hacer ambas cosas.

El comiso penal es familiar para la mayoría de las personas: si el acusado es condenado, la corte ordena la confiscación del producto de su delito y los bienes que usó para cometerlo. En los Estados Unidos, como en la mayor parte de los países, si el acusado ya no tiene el dinero -sea porque lo gastó, lo escondió, o lo envió al extranjero- la corte puede emitir una sentencia basada en el valor de los activos, ordenándole pagar una suma de dinero igual a la que ganó gracias al delito. ${ }^{13}$ (Hay excepciones: Guatemala y Argentina, por ejemplo, no permiten la imposición de sentencias monetarias basadas en el valor de los activos)

Una vez que la corte determina que el imputado ha obtenido productos de su delito, la emisión de una sentencia monetaria es obligatoria. ${ }^{14}$ Además, en muchos países, incluyendo a los Estados Unidos, el Gobierno puede ejecutar esa sentencia basada en el valor de los activos decomisando algo diferente de igual valor, de lo que el imputado sea dueño. En los Estados Unidos, a eso le llamamos "activo sustituto".

El comiso de activos sustitutos también es obligatorio, y puede incluir cualquier bien que le pertenezca al imputado, aun si este no pudiera ser reconducido al delito. ${ }^{15}$

13 United States v. Vampire Nation (2006), rechazando expresamente el argumento de que una orden de comiso debe disponer el comiso de bienes específicos; como tratándose de una orden in personam, puede adoptar la forma de una sentencia por una suma de dinero igual a los productos obtenidos por el imputado a causa del delito, incluso si él ya no los tiene, o cualquiera otros activos, al momento de ser sentenciado; United States v. Hampton (2013), siguiendo a todos los demás circuitos y sosteniendo que el comiso, tratándose de una parte obligatoria de la sentencia del imputado, la corte puede emitir una sentencia monetaria por el monto de los productos del delito aun cuando el imputado haya disipado los bienes rastreables y carece de otros fondos con los que cumplir la sentencia.

14 United States v. Blackman (2014), § 2461(c) hace al comiso penal obligatorio en todos los casos; "la palabra 'deberá' no implica discreción. . . . El texto llano del estatuto indica con ello que el comiso no es un elemento discrecional de la sentencia. . . . en la medida en que la corte de distrito creyó que podía negar el comiso sobre la base de consideraciones de equidad, su razonamiento era equivocado."; United States v. Newman (2011), "Si el gobierno ha satisfecho los requisitos para el comiso penal, la corte de distrito debe imponer comiso penal, sujeto únicamente a limitaciones estatutarias y constitucionales"; $i d$., la corte de distrito carece de discreción para reducir o eliminar el comiso penal obligatorio; revocando la negativa de la corte de distrito de emitir una sentencia monetaria.

15 United States v. Fleet (2007), El Congreso eligió un lenguaje amplio al disponer que cualquier bien del imputado puede ser decomisado como active sustituto; no le está permitido a las cortes "encontrar un equilibrio entre los intereses en conflicto" o forjar excepciones al estatuto; de ese modo, la residencia del imputado puede ser decomisada como activo sustituto a pesar de las leyes estatales sobre heredad y bienes gananciales; United States v. Carroll (2003), para cumplir una sentencia monetaria, se puede ordenar el comiso como activos sustitutos de "hasta el último centavo" que le pertenezca al imputado; United States v. Alamoudi (2006), "La sección 853(p) no es discrecional... [G] uando el Gobierno no puede acceder a los bienes inicialmente sujetos a comiso, la ley federal requiere que una corte sustituya los bienes manchados no disponibles por activos sustitutos". 
Entonces, para obtener una sentencia de comiso como parte de un caso penal, el fiscal seguiría los siguientes pasos:

1. incluir el comiso en la formulación de cargos [indictment];

2. preservar los bienes mientras esté pendiente el juicio;

3. incluir la orden de comiso en la sentencia si el imputado es condenado;

4. lidiar con terceros en un procedimiento accesorio posterior a la condena.

\subsection{Comiso civil}

El comiso no basado en condena (NCB) puede que sea menos familiar. Los casos de comiso no basado en condena son acciones contra los bienes; en los Estados Unidos, la costumbre es designar al bien como el sujeto del caso, razón por la cual nuestros casos no basados en condena tienen nombres graciosos, tales como United States v. An Assortment of Firearms [Estados Unidos contra surtido de armas de fuego] o United States v. $\$ 17,900$ in U.S. Currency [Estados Unidos contra 17.900 dólares en moneda de los Estados Unidos].

Designar al bien como el sujeto de los procedimientos no significa que el bien haya hecho algo malo; el comiso civil es simplemente un mecanismo procedimental diseñado para lograr reunir en la sala de la corte al mismo tiempo a todo aquel que tenga un interés en el bien. ${ }^{16}$ Así, por ejemplo, si el Gobierno se apodera de una suma de dinero, designa al dinero como el sujeto del caso de comiso, publica una notificación e invita a cualquiera que tenga un interés en impugnar el comiso del dinero a comparecer ante la corte para hacerlo.

Para nosotros en los Estados Unidos, este no es un concepto nuevo. Fue desarrollado en el siglo XVIII como una manera de recuperar bienes poseídos por piratas y traficantes de esclavos, cuyas embarcaciones y carga podían ser confiscadas, pero que permanecían fuera de la jurisdicción de los Estados Unidos y sus cortes. Si capturábamos el barco pirata y toda su carga, pero no podíamos capturar al propietario de la nave, simplemente impetrábamos una acción de comiso no basado en condena en contra del barco e invitábamos al pirata a comparecer ante la corte oponerse a la acción. Si se rehusaba a venir no podía ser perseguido; no tenemos condena in absentia; pero podíamos recuperar sus bienes.

Actualmente utilizamos el comiso no basado en condena en toda clase de casos, desde narcotráfico, corrupción, hasta virtualmente cualquier otro tipo de delito. Y a aquéllos que preguntan si todavía lo usamos contra piratas y traficantes de esclavos,

16 United States v. Ursery (1996), Kennedy, J. concurrente, los procedimientos in rem son simplemente estructuras que permiten al Gobierno el establecimiento de título de propiedad a su favor sobre bienes manchados por su origen delictuoso, en un solo procedimiento, en el que a todas las personas interesadas se las requiere para que presenten reclamos oponiéndose al comiso al mismo tiempo; United States v. Real Property Located at 475 Martin Lane (2008), "las acciones in rem generalmente son consideradas procedimientos contra el mundo" en los cuales "la corte busca determinar todas las reclamaciones que cualquiera tenga respecto de la cosa en cuestión". 
les digo, todavía tenemos piratas, solo que les llamamos terroristas; y todavía tenemos traficantes de esclavos, solo que les llamamos traficantes de personas, o personas involucradas en el tráfico sexual.

Lo importante que es preciso saber sobre el comiso civil o no basado en condena es lo siguiente: no requiere una condena o siquiera un caso penal, pero el Gobierno sigue teniendo que probar dos cosas: que se cometió un delito, y que ese bien derivó de ese delito o fue utilizado para cometerlo.

En el caso de los bienes facilitantes, no es necesario que el dueño del bien sea el infractor; alguien más puede haber usado bienes de su propiedad para cometer el delito, pero el propietario puede hacer valer una defensa de dueño inocente. [innocent owner defense]

Entonces, por ejemplo, si alguien usa el auto de su mujer para cometer un delito, y la mujer supo todo lo relativo a dicho delito y dejó que ocurriera, podríamos decomisar el auto en un caso civil sin tener que presentar cargos penales contra la mujer; pero si ella no sabía que su auto estaba siendo usado para cometer un delito, ella tendría una defensa de dueño inocente.

Si el comiso civil es tan maravilloso, ¿por qué el Gobierno no decomisa todo por la vía civil en lugar de incluirlo como parte de un caso penal? O preguntado de otra forma, ¿en base a qué decide el fiscal si presenta el caso en sede penal, como parte de una persecución penal, o separadamente en una acción de comiso no basado en condena?

Primero, puede involucrar una gran cantidad de trabajo adicional llevar el caso separadamente si eso puede hacerse fácilmente habiendo un caso penal-asumiendo que el caso penal se va a mover rápidamente. Pero, además, el comiso no basado en condena tiene una seria limitación.

Recuerden el segundo requerimiento: que el Gobierno debe probar que el bien derivó del delito o fue utilizado para cometerlo. Ya que se trata de una acción contra bienes específicos, en casos de comiso civil no hay activos sustitutos o sentencias basadas en el valor de los activos. Entonces, si el Gobierno no puede establecer la conexión entre el activo específico de que se trate y el delito subyacente, no puede haber comiso. Esto puede ser problemático en cualquier caso, pero particularmente en casos que involucran mecanismos sofisticados de lavado de dinero, en los que esconder la conexión entre el dinero y el delito subyacente fue el objeto del ejercicio completo.

Por esas razones, el comiso no basado en condena generalmente está reservado para casos donde el comiso en sede penal no es posible, donde una sentencia penal sería inapropiada, o donde el caso penal vinculado al comiso no está preparado para la presentación de cargos.

\section{2 ¿Cuándo se usaría el comiso civil?}

Aquí hay una lista corta de las instancias en las que un fiscal en los Estados Unidos podría elegir para perseguir la recuperación de bienes manchados en una acción de comiso no basado en condena en lugar de como parte de una persecución penal: 
1. Cuando el bien es incautado, pero nadie se opone al comiso;

2. Cuando el infractor está muerto o no es competente para ser sometido a juicio;

3. Cuando el imputado es un fugitivo o un nacional de un país extranjero fuera de la jurisdicción de los Estados Unidos; p.ej., él comete un delito en los Estados Unidos y se fuga a otro país dejando su dinero atrás, o comete un delito en otro país y pone el dinero en los Estados Unidos;

4. Cuando la prescripción ha corrido en el caso penal;

5. Cuando hemos recuperado el bien, pero no sabemos quién cometió el delito que da lugar al comiso; este es un problema frecuente en casos en los que un mensajero [courier], o cuando dinero o armas destinadas al terrorismo son interceptadas en tránsito;

6. Cuando el imputado se ha declarado culpable de un delito diferente de aquél que da lugar al comiso; esto es necesario ya que en los Estados Unidos no tenemos el concepto de "confiscación extendida", el que permitiría el comiso de los productos de "otros crímenes" una vez que el imputado ha sido condenado;

7. Cuando no hay un caso penal federal porque el imputado ya ha sido condenado en un estado o corte extranjera o tribal y no hay razones para perseguirlo de nuevo;

8. Cuando no hay caso penal porque los intereses de la justicia no requieren una condena;

9. Cuando la evidencia es insuficiente para probar más allá de toda duda razonable que el imputado cometió el delito;

10. Cuando el imputado utilizó bienes ajenos para cometer el delito y esa persona no es un dueño inocente;

11. Cuando el caso penal no está listo para ser llevado a juicio, pero hay peligro de que el bien desaparecerá.

El procedimiento para decomisar bienes en un caso no basado en condena funciona del siguiente modo:

1. El Gobierno captura los bienes, usualmente con una orden [warrant] emitida por un juez, y notifica de la acción de comiso al dueño de los bienes;

2. Cualquiera que tenga un interés en los bienes puede presentar un reclamo;

3. Si alguien presenta un reclamo, el Gobierno tiene que probar que se cometió un delito y que los bienes derivaron del delito o fueron usados para cometerlo;

4. Si lo hace, el propietario tiene la oportunidad de hacer valer una defensa de dueño inocente - i.e., sosteniendo que no sabía que sus bienes estaban manchados por el delito;

5. Si, al final del día prevalece el Gobierno, la corte decreta una orden de comiso transfiriendo el título de propiedad a los Estados Unidos. 


\section{EJEMPLOS DE GASOS}

Muy brevemente, permítanme dar algunos ejemplos de casos en los que los Estados Unidos han usado el comiso no basado en condena en el contexto internacional. Estos son casos en los que utilizamos comiso no basado en condena porque el delito ocurrió en los Estados Unidos, pero el imputado se encontraba en otro país, o en los que el delito ocurrió en otro país, pero los activos fueron encontrados en los Estados Unidos.

En el caso MegaUpload, un imputado en Nueva Zelanda usó el internet para infringir [to steal] propiedad intelectual protegida por derechos de autor de artistas y productores de películas en los Estados Unidos. Entonces, debido a que los computadores a los que el imputado accedió por Internet se encontraban en los Estados Unidos, los Estados Unidos tenían jurisdicción para perseguir el delito, pero debido a que el imputado era un fugitivo resistiéndose a la extradición, no nos era posible recuperar los bienes por medio de comiso en sede penal. En lugar de ello, pudimos obtener una sentencia de comiso no basada en condena contra su dinero y solicitar que se la ejecutara en Nueva Zelandia y Hong Kong. ${ }^{17}$

En el caso Abacha, el gobernante militar de Nigeria, el general Abacha, se apropió de cuatro billones de dólares pertenecientes a su país, los lavó vía Estados Unidos e intentó esconderlo en cuentas bancarias en Europa occidental. De nuevo, si bien el delito de lavado de dinero ocurrió en los Estados Unidos, no nos era posible perseguir penalmente al imputado, pero podíamos obtener órdenes de comiso no basadas en condena contra los bienes apropiados por este, las que están siendo ejecutadas por otros países, incluyendo a Jersey en las Islas del Canal, donde se encuentran los bienes. ${ }^{18}$

En el caso Prevezon, criminales en Rusia se apropiaron de 230 millones de dólares del tesoro ruso, lo lavaron por medio de los bancos de Europa oriental, y usaron parte del dinero para comprar bienes raíces en Nueva York. En ese caso, el delito tuvo lugar en una multitud de países extranjeros y no pudimos identificar ni capturar a los criminales rusos, pero pudimos interponer una acción de comiso NCB para recuperar los bienes, ya que estaban localizados en Nueva York. ${ }^{19}$

En otro caso, interceptamos millones de dólares que estaban pasando a través de bancos de los Estados Unidos, camino a una compañía china llamada Dandong Zhicheng, que estaba actuando como una fachada para Corea del Norte. El dinero

17 United States v. All Assets Listed in Attachment A (MegaUpload, Ltd.) (2015), fondos derivados de infracción a propiedad intelectual de los Estados Unidos en sitio de internet administrado desde Nueva Zelanda.

18 United States v. All Assets Held in Account Number 80020796 (2015), dos billones de dólares apropiados del Tesoro de Nigeria por el General Abacha, lavados a través de bancos de los Estados Unidos, y depositados en Jersey, Francia y el Reino Unido.

19 United States v. Prevezon Holdings, Ltd. (2017), el patrón temporal de las transacciones puede servir como evidencia circunstancial de que el dinero que se mueve a través de una compleja serie de transacciones es reconducible a la asignación estándar para servicios públicos original. 
estaba destinado al programa de armamento de Corea del Norte, en violación de sanciones internacionales. Nosotros no podíamos perseguir ni a la compañía china ni a los norcoreanos, pero pudimos entablar una acción de comiso no basado en condena para evitar que el dinero llegara a Corea del Norte. ${ }^{20}$

Podría dar muchos otros ejemplos que involucran funcionarios públicos corruptos de países en desarrollo que invierten en los Estados Unidos, bienes culturales hurtados en otros países y encontrados en los Estados Unidos, y equipo militar siendo enviado a terroristas en Medio Oriente, entre otros. ${ }^{21} \mathrm{El}$ punto, sin embargo, es que el comiso no basado en condena puede ser usado en una amplia variedad de casos, y con mucha frecuencia, particularmente en casos internacionales, es la única manera de recobrar los bienes que derivaron del delito o fueron usados para cometerlo.

\section{CUESTIONES CONSTITUGIONALES}

Hay muchas cuestiones constitucionales que han surgido en casos de comiso de activos y no tengo tiempo para discutirlas en detalle, pero hay algunas cuestiones que ameritan una mención de paso. ${ }^{22}$

Primero, la Corte Suprema ha sostenido que el comiso no puede ser extremadamente desproporcionado a la gravedad del delito. Entonces, hay un requerimiento constitucional de proporcionalidad. ${ }^{23}$

Segundo, la Corte ha sostenido que no es constitucionalmente necesario proporcionar una defensa de dueño inocente, pero nuestra legislatura ha impuesto una por estatuto. ${ }^{24}$

Tercero, mientras que la culpabilidad de un imputado en un proceso penal debe ser establecida más allá de toda duda razonable, la Corte Suprema ha sostenido

20 United States v. All Wire Transactions Involving Dandong Zhicheng Metallic Material Co. (2017).

21 Véase United States v. One Gulfstream $G$-V Jet Aircraft (2013), ni los principios de la cortesía internacional ni la doctrina de los actos de Estado obstan a que los Estados Unidos emplee sus leyes de comiso para recuperar bienes comprados en los Estados Unidos con los productos de extorsión, hurto o malversación extranjeros; United States v. Eighteenth Century Peruvian Oil on Canvas (2009), pinturas religiosas de óleo importadas desde Perú en infracción de la Ley de Aplicación de la Convención sobre Bienes Culturales, están sujetas a comiso bajo 19 U.S.C. § 2609; United States v. Two General Electric Aircraft Engines (2016), acción de comiso civil contra dos motores aéreos que estaban siendo enviados a Irán en infracción del derecho de los Estados Unidos y estaban destinados a ser entregados a una organización terrorista: la Fuerza Qods del Cuerpo de la Guardia Revolucionaria Islámica.

22 Para una discusión comprehensiva del desarrollo de las cuestiones constitucionales involucradas en casos de comiso de activos, véase Cassella (2013), capítulo 2.

23 United States v. Bajakajian (1998).

24 Bennis v. Michigan (1996), propietarios inocentes no tienen protección frente al comiso civil bajo la cláusula de debido proceso; a menos que la legislatura establezca por estatuto una defensa de dueño inocente, los bienes pueden ser decomisados sobre la única base de haber sido usados en la comisión de un delito; 18 U.S.C. $§ 983($ d) (proporcionando una defensa estatutaria de dueño inocente en casos de comiso civil). 
que el comiso de sus bienes - tanto en casos penales como en casos de comiso no basado en condena- puede ser establecido por medio de un balance de probabilidades. ${ }^{25}$

Finalmente, la Corte ha sostenido que no hay un derecho constitucional a utilizar bienes manchados para financiar una defensa penal. Entonces, si el Gobierno presenta una prueba preliminar de que los bienes del imputado están manchados, él no puede usarlos para contratar consejo letrado, sino que debe aceptar aquella designada para representarlo a expensas del Gobierno. ${ }^{26}$

\section{CONGLUSIÓN}

Hemos encontrado que el comiso de activos es una poderosa, incluso esencial, herramienta para hacer cumplir la ley en los Estados Unidos, y espero que gracias al trabajo conjunto y compartiendo recíprocamente nuestras experiencias podamos hacerlo funcionar de la mejor manera para todos nosotros.

25 Libretti v. United States (1995), "el comiso penal es un aspecto del castigo impuesto tras una condena por una infracción penal sustantiva"; United States v. DeFries (1997), a la luz de Libretti, la carga de la prueba en el caso RICO es la de preponderancia de evidencia.

26 United States v. Monsanto (1989), afirmando la restricción prejudicial de los productos del delito sin exención para los honorarios de abogado. 


\section{BIBLIOGRAFÍA CITADA}

Cassella, Stefan D. (2013). Asset Forfeiture Law in the United States (Juris, 2a ed.). 


\section{JURISPRUDENCIA CITADA}

\section{Estados Unidos:}

United States v. Monsanto, 491 U.S. 600 (1989). Corte Suprema de los Estados Unidos.

United States v. Rivera, 884 F.2d 544, 546 (11th Cir. 1989). Corte de Apelaciones para el Onceavo Circuito.

United States v. Harris, 903 F.2d 770, 777 (10th Cir. 1990). Corte de Apelaciones para el Décimo Circuito.

United States v. Schifferli, 895 F.2d 987, 990-91 (4th Cir. 1990). Corte de Apelaciones para el Cuarto Circuito.

Libretti v. United States, 516 U.S. 29, 39 (1995). Corte Suprema de los Estados Unidos.

Bennis v. Michigan, 516 U.S. 442, 446 (1996). Corte Suprema de los Estados Unidos.

United States v. McHan, 101 F.3d 1027, 1041-42 (4th Cir. 1996). Corte de Apelaciones para el Cuarto Circuito.

United States v. Ursery, 518 U.S. 267, 295-96 (1996). Corte Suprema de los Estados Unidos.

United States v. DeFries, 129 F.3d 1293, 1312 (D.C. Cir. 1997). Corte de Apelaciones para el Circuito del Distrito de Columbia.

United States v. Bajakajian, 524 U.S. 321, 323 (1998). Corte Suprema de los Estados Unidos.

United States v. Farrett, 133 F.3d 519, 530-31 (7th Cir. 1998). Corte de Apelaciones para el Séptimo Circuito.

United States v. Keeling, 235 F.3d 533, 537 (10th Cir. 2000). Corte de Apelaciones para el Décimo Circuito.

United States v. Carroll, 346 F.3d 744, 749 (7th Cir. 2003). Corte de Apelaciones para el Séptimo Circuito.

United States v. Singh, 390 F.3d 168, 190 (2d Cir. 2004). Corte de Apelaciones para el Segundo Circuito.

United States v. Betancourt, 422 F.3d 240, 251 (5th Cir. 2005). Corte de Apelaciones para el Quinto Circuito.

United States v. Huber, 404 F.3d 1047 (8th Cir. 2005). Corte de Apelaciones para el Octavo Circuito.

United States v. Fuluke, 426 F.3d 323, 326 (5th Cir. 2005). Corte de Apelaciones para el Quinto Circuito. 
United States v. Segal, 432 F.3d 767, 779 (7th Cir. 2005). Corte de Apelaciones para el Séptimo Circuito.

United States v. Alamoudi, 452 F.3d 310, 314 (4th Cir. 2006). Corte de Apelaciones para el Cuarto Circuito.

United States v. Ortiz-Cintron, 461 F.3d 78, 80 (1st Cir. 2006). Corte de Apelaciones para el Primer Circuito.

United States v. Vampire Nation, 451 F.3d 189, 202 (3d Cir. 2006). Corte de Apelaciones para el Tercer Circuito.

United States v. Fleet, 498 F.3d 1225, 1231 (11th Cir. 2007). Corte de Apelaciones para el Onceavo Circuito.

United States v. Real Property Located at 475 Martin Lane, 545 F.3d 1134,1144 (9th Cir. 2008). Corte de Apelaciones para el Noveno Circuito.

United States v. Eighteenth Century Peruvian Oil on Canvas, 597 F. Supp.2d 618, 623 (E.D. Va. 2009). Corte Distrital para el Distrito Este de Virginia.

United States v. Heilman, 377 Fed. Appx. 157, 211 (3d Cir. 2010). Corte de Apelaciones para el Tercer Circuito.

United States v. Warshak, 631 F.3d 266, 329-330 (6th Cir. 2010). Corte de Apelaciones para el Sexto Circuito.

United States v. $\$ 7708.78$ in U.S. Currency, 2011 WL 3489835, *3 (S.D. Miss. 2011). Corte Distrital para el Distrito Sur de Mississippi, 9 de Agosto de 2011.

United States v. Diaz, 413 Fed. Appx. 704, 708 (5th Cir. 2011). Corte de Apelaciones para el Quinto Circuito.

United States v. Martin, 662 F.3d 301, 309 (4th Cir. 2011). Corte de Apelaciones para el Cuarto Circuito.

United States v. Newman, 659 F.3d 1235, 1240 (9th Cir. 2011). Corte de Apelaciones para el Noveno Circuito.

United States v. Olguin, 634 F.3d 384, 398-99 (5th Cir. 2011). Corte de Apelaciones para el Quinto Circuito.

United States v. Torres, 703 F.3d 194, 199 (2d Cir. 2012). Corte de Apelaciones para el Segundo Circuito.

United States v. Colon, 522 Fed. Appx. 61, 63 (2d Cir. 2013). Corte de Apelaciones para el Segundo Circuito.

United States v. Hampton, 732 F.3d 687, 691-92 (6th Cir. 2013). Corte de Apelaciones para el Sexto Circuito.

United States v. One Gulfstream G-V Jet Aircraft, 941 F. Supp.2d 1, 11 - 12 (D.D.C. 2013). Corte Distrital para el Distrito de Columbia.

United States v. Peters, 732 F.3d 93, 98-99, 101-102 (2d Cir. 2013). Corte de Apelaciones para el Segundo Circuito. 
Kaley v. United States, 134 S. Ct. 1090 (2014). Corte Suprema de los Estados Unidos.

United States v. Blackman, 746 F.3d 137, 143 (4th Cir. 2014). Corte de Apelaciones para el Cuarto Circuito.

United States v. Martin, 2014 WL 221956, *5 (D. Idaho 2014). Corte Distrital para el Distrito de Idaho, 21 de Enero de 2014.

United States v. Smith, 749 F.3d 465, 488-89 (6th Cir. 2014). Corte de Apelaciones para el Sexto Circuito.

United States v. All Assets Held in Account Number 80020796, 83 F. Supp.3d 360 (D.D.C. 2015). Corte Distrital para el Distrito de Columbia.

United States v. All Assets Listed in Attachment A (MegaUpload, Ltd.), 89 F. Supp.3d 813 (E.D. Va. 2015). Corte Distrital para el Distrito Este de Virginia.

United States v. Two General Electric Aircraft Engines, 2016 WL 6495397 (D.D.C. 2016). Corte Distrital para el Distrito de Columbia, 2 de Noviembre de 2016.

United States v. All Wire Transactions Involving Dandong Zhicheng Metallic Material Co., 2017 WL 3233062 (D.D.C. 2017). Corte Distrital para el Distrito de Columbia, 22 de Mayo de 2017.

United States v. Prevezon Holdings, Ltd., 251 F.Supp.3d 684 (S.D.N.Y. 2017). Corte Distrital para el Distrito Sur de Nueva York. 
